\title{
INFORMATION AND ANALYTICAL SYSTEM FOR PROFESSIONAL PUBLIC ACCREDITATION OF AGRICULTURAL PROGRAMS IN RUSSIA
}

\author{
Mikhail Petropavlovskiy ${ }^{1}$ and Olga Nefedova ${ }^{2}$ \\ ${ }^{1}$ Doctor of Engineering Science, Mari State University, Russia, mv2006-68@mail.ru \\ ${ }^{2}$ Candidate of Engineering Science, Mari State University, Russia, olga-5@inbox.ru
}

\begin{abstract}
The article considers the information and analytical system for professional public accreditation of agricultural programs in Russia developed within the project "Development of Public Accreditation of Agricultural Programs in Russia, PACAgro" funded under the European Union Program TEMPUS.

The procedure of professional public accreditation includes several stages: preparation by the educational organization of a self-evaluation report on the study programs declared for professional public accreditation, submitting an application for accreditation by the educational institution, the preparation for review, the procedure of external review at the educational organization, procedure of accreditation decision-making by the Accreditation Board and data input into the Register of accredited study programs, publication of the Register.
\end{abstract}

The information and analytical system provides among other things an automated performance of each stage.

Keywords: professional public accreditation, information and analytical system, accreditation indicators.

\section{INTRODUCTION}

In Russia, professional public accreditation of professional study programs shall be the recognition that the quality and level of training of graduates who have mastered such a study program at a particular educational organization meet the requirements of professional standards and labor market for workers and employees of the corresponding specialization (Federal Law "On Education in the Russian Federation", Art. 96, par. 4).

It can be noted that professional public accreditation is aimed at evaluating the graduates' learning outcomes as opposed to state accreditation of educational activities, whose purpose is "to confirm that educational activities and students' training on basic study programs delivered by educational organizations, organizations that provide training correspond to the federal state educational standards" (Federal Law "On Education in the Russian Federation", Art. 92, par. 2). The drawback of the existing state accreditation system is the lack of mechanisms for an objective assessment of the final result of the study program implementation and its compliance with the labor market requirements. 
In accordance with the Law, professional public accreditation must be carried out by employers, their associations or organizations authorized by them. The procedure for professional public accreditation of professional study programs, its forms and evaluation methods in use, as well as the follow-up process are also established by an employer, employers' association or organization authorized by them to carry out this accreditation.

\section{MATERIALS AND STUDY METHODS}

Within the project "Development of Public Accreditation of Agricultural Programs in Russia, PACAgro" funded under the European Union Program TEMPUS a system of professional public accreditation of agricultural programs is being established (Web site of the Project). The project activities are aimed at developing methods and procedures for accreditation of agricultural programs, an information and analytical system for professional public accreditation of agricultural programs, as well as methodological support of the accreditation procedure.

Currently in Russia over 100 HEls deliver agricultural programs, about half of them are specialized (agrarian universities, academies and institutes), others - implement programs on a wide range of training fields. About 1,500 agricultural programs are delivered by these HEls.

An information and analytical system of professional public accreditation of agricultural programs has been developed within the project framework to enhance the efficiency of the system for evaluation of professional study programs, to increase the transparency of results, and to keep all stakeholders informed.

The information and analytical system is based on the accreditation indicators developed in line with the Standards and Guidelines for Quality Assurance in the European Higher Education Area (ESG), as well as the requirements of professional standards and employers for graduates' training:

\section{Indicator 1. Study program}

- participation of employers in the study program development;

- structure and content of the study program curriculum provided for the achievement of competences and conferred qualifications;

- system for assessing learning outcomes;

- efficiency of the applied teaching methods;

- teaching and learning support of the study program;

- graduate qualification works, scientific research projects;

- providing the implementation of curriculum and its improvement.

\section{Indicator 2. Students and graduates}

- level of knowledge /competences of students and graduates;

- system for assessing students and graduates' knowledge/competences;

- student support services;

- employment of students;

- satisfaction of employers;

- satisfaction of students.

\section{Indicator 3. Academic staff}

- compliance of the academic staff qualification and number to the curriculum;

- involving employers in teaching;

- professional development of teachers;

- availability of the system for diagnosis and motivation of the academic staff.

\section{Indicator 4. Facilities and resources}

- provision of the study program with classrooms, laboratories and equipment;

- improvement and enlargement of facilities and resources; 
- engagement of employers in providing the necessary base for the implementation of the educational process.

\section{Indicator 5. Organization and management}

- management of the study program;

- availability of the system for collection, analysis and use of the information when managing the study program (Petropavlovskiy, 2016, p. 682).

The accreditation procedure contemplates the participation of employers and students' representatives at the stages of internal and external evaluation of study programs.

The main organizational unit of the system is the Agency for Professional Public Accreditation of Agricultural Programs. The Agency's activities comply with the requirements for external quality assurance agencies established by ENQA.

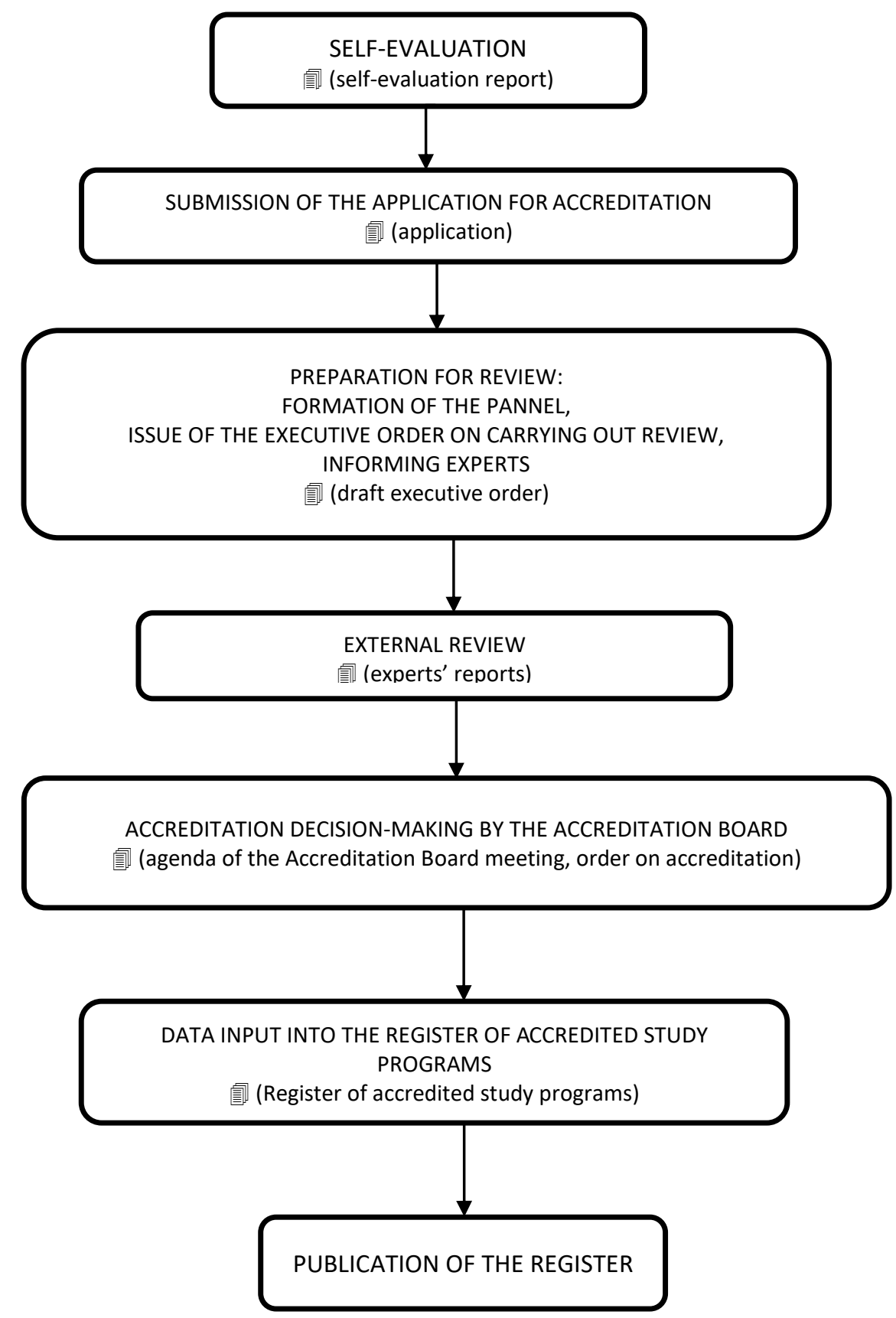

Fig. 1. General scheme of the procedure of professional public accreditation 
The procedure of professional public accreditation includes several stages (Figure 1). The initial stage is the preparation by the educational organization of a self-evaluation report on the study programs declared for professional public accreditation. Then comes the stage of submitting an application for accreditation by the educational institution. The next procedure performed by the accreditation agency is the preparation for review: an expert panel is formed out of experts listed in the Database of experts; an executive order on carrying out accreditation is issued and experts get informed. The next stage includes the procedure of external review at the educational organization, during which experts prepare their reports with the conclusions on compliance or non-compliance of the quality of students' training with professional standards. Further comes the procedure of accreditation decision-making by the Accreditation Board and data input into the Register of accredited study programs. The final stage of professional public accreditation is the publication of the Register.

The information and analytical system representing a web resource posted on the Internet at www.marsu.ru/pacagro/, provides among other things an automated performance of each stage mentioned above.

Databases of

- Organizations

- Experts

- $\quad$ Register of accredited study programs (RASP)

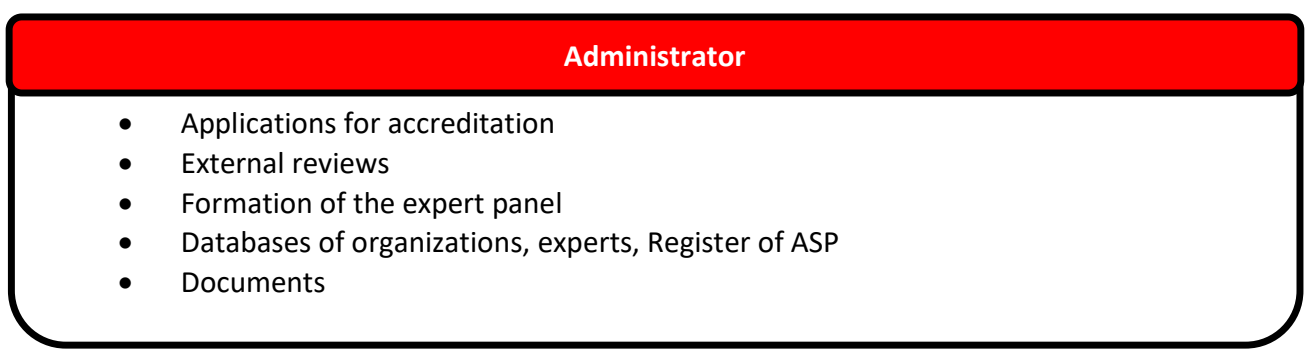

\begin{tabular}{|ll|}
\hline & Expert \\
\hline & Database of experts \\
\hline & External reviews \\
\hline & Register of ASP \\
\hline & Documents \\
\hline
\end{tabular}

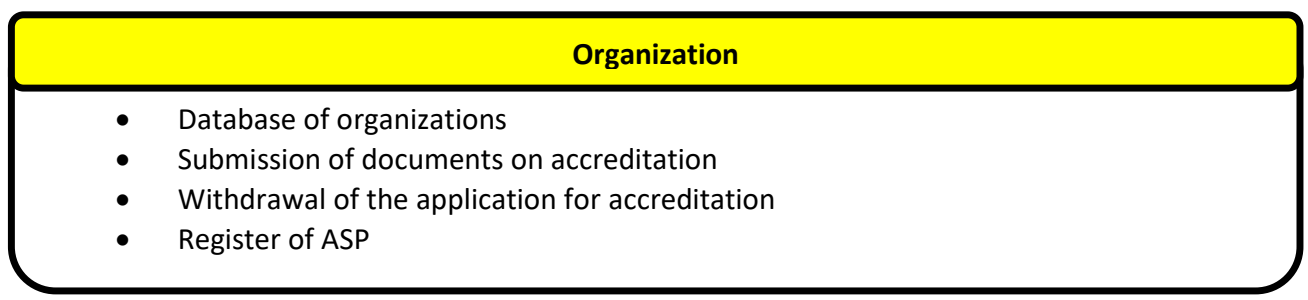

Unauthorized user

- $\quad$ Register of accredited study programs (RASP)

Fig. 2 Features of the information and analytical system

The system works with databases (Figure 2): educational organizations (information about HEls that are to undergo/are undergoing/have undergone professional public accreditation of agricultural programs), experts (data on experts who have the necessary competence to carry out external reviews of agricultural programs 
during professional public accreditation), Register of accredited study programs.

There are 4 groups of users distinguished when working with the system. They have different rights:

- administrator;

- expert;

- organization;

- unauthorized user.

Administrator uses the following system functions (Fig. 2):

1) receives applications for accreditation from educational organizations;

2) manages the information on current, upcoming and past reviews;

3) selects experts in accordance with their competence for work in the expert panel;

4) maintains (creates accounts, corrects, views, deletes) databases of educational organizations, experts, Register of accredited study programs;

5) downloads and views documents necessary for internal (application, self-evaluation report) and external review (executive order on the expert panel's work, expert panel's report, orders on accreditation results).

Expert makes use of the following functions:

1) views and partially edits ("personal data") of the experts' database;

2) views the information on the conducted reviews (past/current/upcoming);

3) views the Register of accredited study programs;

4) views and works with documents (self-evaluation report, external review reports).

Educational organizations, who have received a system-access password have the opportunity to:

1) view and partially edit ("personal data") the organizations' database;

2) submit documents for accreditation - data input and generation of the application for professional public accreditation, download of the self-evaluation report, viewing of the application processing;

3) withdraw the application for professional public accreditation;

4) view the Register of accredited study programs.

The rest of unauthorized users have the opportunity only to view the register of accredited study programs.

\section{RESULTS AND DISCUSSION}

Structurally, the system includes a data collection and storage subsystem and a data publishing subsystem containing accreditation decisions, since in addition to the collection, storage and processing of the information on accredited study programs, the system allows for an automated preparation of materials for carrying out professional public accreditation and publication of the procedure results. The data entered in the information and analytical system is suggested to be used both when preparing analytical materials for the meetings of the Accreditation Board on professional public accreditation of agricultural programs to take a decision on accreditation of study programs, and for the preparation of reports and analytical reports delivered to stakeholders.

\section{CONCLUSIONS}

The information and analytical system for professional public accreditation of agricultural programs in Russia was tested (and endorsed) in the process of study programs accreditation in the HEls - the TEMPUS project participants: Saint-Petersburg State Agrarian University, Kazan State Agrarian University, Russian State Agrarian University - Moscow Timiryazev Agricultural Academy.

The analysed information and analytical system can be used by a quality assurance agency (accreditation agency) in professional public accreditation of different study program profiles. When the accreditation indicators are being developed, they must consider program profiles.

\section{ACKNOWLEDGEMENT}

This research was financially supported by TEMPUS project "Development of Public Accreditation of Agricultural Programs in Russia" (543902-TEMPUS-1-2013-SK-TEMPUS-SMGR). 


\section{REFERENCE LIST}

Web site of the Project "Development of Public Accreditation of Agricultural Programs in Russia". URL: http://pacagro.uniag.sk/.

Standards and Guidelines for Quality Assurance in the European Higher Education Area (2015).

Petropavlovskiy M., Nefedova O., Smelik V. (2016). Evaluation of the indicators of professional public accreditation of agricultural study programs. The Agri-Food Value Chain: Challenges for Natural Resources Management and Society. Pp. 681-687. URL:

http://spu.fem.uniag.sk/mvd2016/proceedings/en/articles/s8/petropavlovskiy_nefedova_smelik.pdf. (DOI: http://dx.doi.org/10.15414/isd2016.s8.15)

Petropavlovskiy M., Smelik V., Nefedova O. (2015). About the Creation of the System for Professional Public Accreditation of Agricultural Programs. "Development of Public Accreditation of Agricultural programs in Russia (PACAgro)» (543902-TEMPUS-1-2013-1-SK-TEMPUS-SMGR): Collection of scientific papers. Pp. 20-27.

Horská E., Petropavlovskiy M., Nefedova O., Smelik V., Dobrinov A., Ovchinnikova E. et al. (2015). Perspective Plan for Professional Accreditation of Agricultural Programs Based on the Analysis of the Quality Assurance System in the Russian Federation. - Nitra - Saint Petersburg. 320 p.

Petropavlovskiy M., Garifullina F., Nefedova O. (2017). Recognition of Quality Assurance Agencies' Activity on the European Level. "Development of Public Accreditation of Agricultural programs in Russia (PACAgro)» (543902-TEMPUS-1-2013-1-SK-TEMPUS-SMGR): Collection of scientific papers. StPet., SPbSAU. Pp. 26-30. 